\title{
Is 4-Hydroxynonenal a Predictive Parameter for the Development of Joint Erosion in Patients With Rheumatoid Arthritis?
}

\author{
Gürkan AKGÖL, ${ }^{1}$ Hasan ULUSOY, ${ }^{2}$ Selda TELO, ${ }^{3}$ Arif GÜLKESEN, ${ }^{1}$ \\ Tülay YILDIRIM, ${ }^{4}$ Ahmet Kürşad POYRAZ, ${ }^{5}$ Arzu KAYA ${ }^{1}$ \\ ${ }^{1}$ Department of Physical Medicine and Rehabilitation, Medical Faculty of Firat University, Elazı̆̆, Turkey \\ ${ }^{2}$ Department of Rheumatology, Medicana International Samsun Hospital, Samsun, Turkey \\ ${ }^{3}$ Department of Biochemistry and Clinical Biochemistry, Medical Faculty of Firat University, Elazı̆̆, Turkey \\ ${ }^{4}$ Department of Physical Medicine and Rehabilitation, Medical Faculty of İnonü University, Malatya, Turkey \\ ${ }^{5}$ Department of Radiology, Medical Faculty of Firat University, Elazı̆̆, Turkey
}

\begin{abstract}
Objectives: This study aims to evaluate serum 4-hydroxynonenal (4-HNE) levels and its clinical and radiological significance in patients with rheumatoid arthritis (RA).

Patients and methods: The study included 40 patients ( 8 males, 32 females; mean age $51.4 \pm 11.2$ years; range 24 to 72 years) with RA and 30 healthy controls ( 8 males, 32 females; mean age 53.0 111.7 years; range 24 to 72 years. Serum 4-HNE levels were measured using sandwich enzyme-linked immunosorbent assay method. Patients with disease activity score $28 \leq 3.2$ and $>3.2$ were allocated into low and high/moderate disease activity groups, respectively. Additionally, patients were divided into two groups as early RA (disease duration $\leq 2$ years) and established RA (disease duration $\geq 2$ years). Functional disability was evaluated using health assessment questionnaire. Radiographs were scored using the modified Larsen scoring. Results: Serum 4-HNE levels in patients with RA were significantly higher than controls ( $p=0.001)$. Serum 4-HNE levels did not correlate with laboratory or clinical parameters of disease activity including erythrocyte sedimentation rate, C-reactive protein, disease activity score 28 , and health assessment questionnaire. Serum 4-HNE levels were higher in patients with established RA than patients with early RA ( $r=0.487, p=0.001)$. Besides, modified Larsen score which indicates structural damage correlated significantly with serum 4-HNE levels ( $p=0.001)$.

Conclusion: These results indicate that serum 4-HNE levels may be used as an indicator for structural damage such as erosions in the early stage of $\mathrm{RA}$; however, they are not efficient to monitor disease activity.

Keywords: 4-hydroxynonenal; disease activity; modified Larsen score; rheumatoid arthritis.
\end{abstract}

Rheumatoid arthritis (RA) is a chronic, autoimmune multisystem disease with unknown etiology which affects nearly $1 \%$ to $2 \%$ of the world population. RA is characterized by chronic inflammation of the synovial membranes of the joints. Pain and swelling of hand joints are generally the first manifestations of the disease. Activated inflammatory mediators infiltrate synovial membranes and exert deleterious effects on bone and cartilage. ${ }^{1}$ In recent years, numerous studies have investigated the probable role of reactive oxygen species (ROS) in the etiology and pathogenesis of RA..$^{2,3}$ ROS involve apparently in the pathogenesis of various diseases including RA. ${ }^{4}$ ROS are considered as the mediators of tissue damage in patients with RA. ${ }^{5}$ Numerous activated neutrophils which produce ROS accumulate in the synovial fluid of inflamed rheumatoid joint. ${ }^{4}$ Normally, reactive oxygen radicals are produced in all cells and tissues as a result of relatively low-levels of oxidative process. Under normal conditions, ROS production is controlled 
by various antioxidant mechanisms. However, excessive production of ROS and/or inadequate elimination from the environment leads to oxidative stress which may cause severe metabolic functional disorders and damage of the biological macromolecules. ${ }^{6}$ Besides, decompression of peroxidized lipid may induce various end-products containing 4-hydroksynonenal (4-HNE). Increased levels of 4-HNE have been demonstrated in serum (or plasma) and synovial fluid of patients with RA. 7,8

The 4-HNE is one of the aldehydes specific to lipid peroxidation. 4-HNE is believed to be predominantly responsible from the cytopathologic effects seen during oxidative stress. ${ }^{9,10}$ Any factor compatible with stress or activity of antioxidant enzymes may trigger potentially dangerous metabolic pathway of peroxidative damage. Peroxidative damage induced by free radicals has been demonstrated to play role in the pathogenesis of RA, systemic lupus erythematosus, progressive systemic sclerosis, diabetes mellitus type 1 , and myasthenia gravis. Increased oxidative stress has been associated with increased lipid peroxidation in these patients. Lipid peroxidation occurs as a result of increased oxidative stress stemming from deranged pro-oxidant/anti-oxidant balance and represents an important pathogenic process in the oxygen toxicity. As a result of lipid peroxidation increases in the levels of conjugated diens, isoprostanes, 4-HNE and malondialdehyde have been demonstrated. ${ }^{11}$ On the other hand, the etiology of structural damage like bone erosion and joint deformity has not been fully understood in RA. Cartilage and bone damage is associated with activation of free radicals, proinflammatory cytokines and metalloproteinases. Inflammatory cells as macrophages, T-cells, B-cells and neutrophils accumulate in inflamed synovial membrane. ${ }^{11}$ Many researchers have focused on oxidative stress and increased tendency of RA patients to lipid peroxidation for the last few years. ${ }^{3}$

Although various studies have been performed on antioxidant vitamins and enzymes in inflammatory diseases, ${ }^{6,12,13}$ limited number of studies have focused on lipid peroxidation status and inflammatory parameters in patients with RA. Determination of the pathologic mechanism has a special importance in the early diagnosis and treatment of RA. Therefore, in this study, we aimed to evaluate 4-HNE levels and its clinical and radiological significance in patients with $R A$.

\section{PATIENTS AND METHODS}

The study included 40 patients ( 8 males, 32 females; mean age $51.4 \pm 11.2$ years; range 24 to 72 years) with RA who met American Collage Rheumatology classification criteria for RA and who were followed at least for one year at Department of Physical Medicine and Rehabilitation Firat University Hospital, between October 2015 and January 2016 and 30 healthy controls (8 males, 32 females; mean age $53.0 \pm 11.7$ years; range 24 to 72 years). ${ }^{14}$ Patients who were using biologic agents or leflunomide were excluded. As a prerequisite, any change in disease modifying anti-rheumatic drugs (DMARDs) within three months was accepted as an exclusion criterion (apart from changes in drug dosages). Other exclusion criteria were any diagnosis of autoimmune disease other than RA, acute and chronic infections, malignancies, serious pulmonary, hepatic, kidney or endocrinological diseases, smoking, and hypertension (arterial blood pressure $\geq 140 / 90 \mathrm{mmHg}$ or use of antihypertensive drugs) or hypercholesterolemia. The study was approved by the local ethics committee and written informed consent forms were obtained from all participants. The study was conducted in accordance with the principles of the Declaration of Helsinki.

Severity of pain, fatigue and patient and physicians global assessments of disease activity were assessed on a visual analog scale. Duration of morning stiffness was noted in minutes. Disease activity was evaluated using disease activity score $28 .{ }^{15}$ Patients with disease activity scores 28 of $\leq 3.2$ and $>3.2$ were evaluated as having low disease activity and high/moderate disease activity, respectively. ${ }^{16}$ Additionally, patients were divided into two groups as early RA (disease duration $\leq 2$ years) and established $R A$ (disease duration $\geq 2$ years). Functional disability was evaluated using health assessment questionnaire. ${ }^{17}$

Routine laboratory test results were recorded including erythrocyte sedimentation rate, blood chemistry, whole blood cell count, and urinalysis. 
Rheumatoid factor and C-reactive protein levels were measured using nephelometric methods.

Venous blood samples drawn from the patients and controls were centrifuged at $3000 \mathrm{rpm}$ for 10 minutes. The sera were kept at $-20{ }^{\circ} \mathrm{C}$ until the analysis. For the measurement of 4-HNE levels, sandwich enzyme-linked immunosorbent assay method was applied using commercial kits (Sunred, catalogue No: 201-12-1979, Shanghai Sunred Biological Technology Co., Ltd, Shanghai, China).

Standard plain hand radiographs of the patients which were taken within last six months were examined. Structural damage in hand radiographs were evaluated by a radiologist who was blinded to patients' clinical and laboratory data. Radiographs were scored using the modified Larsen scoring which scores 24 areas in both hands (each area 0 to 5 points, total score 0 to 120 points). ${ }^{18}$

\section{Statistical analysis}

Statistical analysis of the study was performed using SPSS Statistics for Windows version 20.0 program (IBM Corporation, Armonk, NY, USA). The results of the study were evaluated using parametric and nonparametric statistical methods for data with normal and non-normal distribution, respectively. Intergroup comparisons were performed using independent groups t test for parametric and Mann-Whitney $U$ test for non-parametric values. Correlations between parameters were evaluated using Spearman correlation coefficient. A $p$ value of $<0.05$ was accepted as the level of significance in statistical evaluations. The results were expressed as mean \pm standard deviation.

\section{RESULTS}

There was no statistically significant difference between patients with RA and controls in terms of age and sex $(p=0.890$ and $p=0.511$, respectively) (Table 1). Mean disease duration was $5.52 \pm 4.56$ years and 26 patients (65\%) were rheumatoid factor positive. All patients were taking low or moderate dose corticosteroid treatment. Mean prednisolone dose was $7.5 \pm 3.4(2.5-20) \mathrm{mg} /$ day. Eleven patients $(40.7 \%)$ were on prednisolone monotherapy, the rest (59.3\%) was taking methotrexate (MTX), sulfasalazine and hydroxychloroquine alone or in combination with DMARDs or prednisolone.

Serum 4-HNE levels $(p=0.001)$ were significantly higher in patients with RA than those of the controls (Table 1). Serum 4-HNE $(p=0.649)$ levels were similar between moderate/

Table 1. Comparison of demographic, clinical and laboratory parameters between patient and control groups

\begin{tabular}{|c|c|c|c|c|c|c|c|}
\hline & \multicolumn{3}{|c|}{ Rheumatoid arthritis $(n=40)$} & \multicolumn{3}{|c|}{ Controls $(n=30)$} & \multirow[b]{2}{*}{$p$} \\
\hline & $\mathrm{n}$ & Mean \pm SD & Min-Max & $\mathrm{n}$ & Mean \pm SD & Min-Max & \\
\hline Age (years) & & $51.4 \pm 11.2$ & $24-72$ & & $53.0 \pm 11.7$ & $24-72$ & 0.890 \\
\hline Sex & & & & & & & 0.511 \\
\hline Female & 32 & & & 22 & & & \\
\hline Male & 8 & & & 8 & & & \\
\hline Duration of the disease (years) & & $5.5 \pm 4.6$ & $1-18$ & & & & \\
\hline Morning stiffness (min.) & & $78.4 \pm 65.9$ & $10-240$ & & & & \\
\hline Pain (0-100 mm VAS) & & $50.6 \pm 24.7$ & $12-94$ & & & & \\
\hline Fatigue (0-100 mm VAS) & & $55.1 \pm 24.1$ & $21-100$ & & & & \\
\hline Patients global (0-100 mm VAS) & & $51.0 \pm 24.7$ & $8-100$ & & & & \\
\hline Physicians global (0-100 mm VAS) & & $46.7 \pm 30.6$ & $5-96$ & & & & \\
\hline Number of the swollen joints $(0-28)$ & & $1.2 \pm 2.2$ & $0-10$ & & & & \\
\hline Number of the tender joints $(0-28)$ & & $4.1 \pm 4.4$ & $0-17$ & & & & \\
\hline Erythrocyte sedimentation rate $(\mathrm{mm} / \mathrm{h})$ & & $30.8 \pm 15.3$ & $6-68$ & & $19.9 \pm 6.8$ & $3-29$ & 0.001 \\
\hline C-reactive protein (g/dL) & & $23.5 \pm 23.5$ & 3-109 & & $3.8 \pm 0.6$ & $3.36-4.87$ & 0.001 \\
\hline Rheumatoid factor (IU/mL) & & $157.2 \pm 241.8$ & $10-949$ & & $9.8 \pm 0.6$ & $8.69-10.30$ & 0.001 \\
\hline Serum 4-HNE (pg/mL) & & $1.4 \pm 0.3$ & $0.98-2.01$ & & $1.1 \pm 0.1$ & $0.78-1.40$ & 0.001 \\
\hline Disease Activity Score 28 & & $4.1 \pm 1.5$ & $1.96-7.03$ & & & & \\
\hline Health Assessment Questionnaire 20 (0-3) & & $1.3 \pm 0.8$ & $0.00-3.00$ & & & & \\
\hline Modified Larsen Score (0-120) & & $30.3 \pm 23.6$ & $8-114$ & & & & \\
\hline
\end{tabular}


Table 2. Comparisons of patients with high/moderate and low disease activity

\begin{tabular}{|c|c|c|c|c|c|c|c|}
\hline & \multicolumn{3}{|c|}{ High/moderate disease activity $(n=23)$} & \multicolumn{3}{|c|}{ Low disease activity $(n=17)$} & \multirow[b]{2}{*}{$p$} \\
\hline & $\mathrm{n}$ & Mean \pm SD & Min-Max & $\mathrm{n}$ & Mean \pm SD & Min-Max & \\
\hline Age (years) & & $50.9 \pm 12.8$ & 24-72 & & $52.1 \pm 8.8$ & $37-67$ & 0.157 \\
\hline Sex & & & & & & & 0.631 \\
\hline Female & 19 & & & 13 & & & \\
\hline Male & 4 & & & 4 & & & \\
\hline Duration of the disease (years) & & $5.5 \pm 3.8$ & $1-16$ & & $5.5 \pm 5.5$ & $1-18$ & 0.441 \\
\hline Prednisolone (mg/day) & & $7.7 \pm 3.6$ & $2.5-20$ & & $6.5 \pm 2.5$ & $2.5-10$ & 0.261 \\
\hline Methotrexate (mg/week) & & $11.9 \pm 2.1$ & $10-15$ & & $10.4 \pm 2.0$ & $7.5-15$ & 0.092 \\
\hline Erythrocyte sedimentation rate $(\mathrm{mm} / \mathrm{h})$ & & $37.1 \pm 15.6$ & $17-68$ & & $22.2 \pm 9.9$ & 3-33 & 0.004 \\
\hline C-reactive protein $(\mathrm{g} / \mathrm{dL})$ & & $35.7 \pm 24.3$ & $8-109$ & & $7.0 \pm 5.4$ & $3-22$ & 0.001 \\
\hline Serum 4-HNE (pg/mL) & & $1.4 \pm 0.3$ & $0.99-2.01$ & & $1.4 \pm 0.3$ & $0.98-1.79$ & 0.649 \\
\hline
\end{tabular}

high and low disease activity RA subgroups (Table 2). Besides, serum 4-HNE levels were higher in established RA patients than early $\mathrm{RA}$ patients $(1.52 \pm 0.26$ vs. $1.20 \pm 0.16 \mathrm{pg} / \mathrm{mL}$, $\mathrm{p}=0.001$ ) (Table 3).

Serum 4-HNE levels correlated significantly with disease duration in RA $(r=0.613, p=0.001)$. However, they did not correlate with any other laboratory or clinical parameters of disease activity. Serum rheumatoid factor levels did not correlate with 4-HNE levels. However, a significant correlation was detected between modified Larsen scores and serum 4-HNE levels $(\mathrm{r}=0.487, \mathrm{p}=0.001)$.

Serum 4-HNE levels were similar between patients taking prednisolone alone or combined with MTX $(p=0.153)$ (Table 4). Similarly, serum 4-HNE levels were comparable between patients MTX and other DMARDs ( $p=0.864)$.

\section{DISCUSSION}

Our study revealed that 4-HNE levels were higher in patients with RA compared to healthy individuals and higher in established RA than early RA. Moreover, 4-HNE levels were associated with joint damage assessed by modified Larsen scores.

Rheumatoid arthritis is an important cause of morbidity. The role of ROS in the pathophysiology of the inflammation has been well established. ${ }^{19,20}$ Aberrant oxidative stress has been considered to have an important role in the pathogenesis of autoimmune diseases by impairing immunological tolerance, inducing apoptotic cell death, and increasing inflammation. ${ }^{21}$ Selley et al. ${ }^{8}$ showed markedly higher 4-HNE levels in patients with RA when compared with osteoarthritic patients. Remarkably higher levels of end products related

Table 3. Data for early and established rheumatoid arthritis

\begin{tabular}{|c|c|c|c|c|c|c|c|}
\hline & \multicolumn{3}{|c|}{ Early RA (<2 years) ( $n=13)$} & \multicolumn{3}{|c|}{ Established RA ( $>2$ years) $(n=27)$} & \multirow[b]{2}{*}{$p$} \\
\hline & $\mathrm{n}$ & Mean \pm SD & Min-Max & $\mathrm{n}$ & Mean \pm SD & Min-Max & \\
\hline Age (years) & & $51.2 \pm 11.6$ & & & $51.6 \pm 11.5$ & & 0.917 \\
\hline Sex & & & & & & & 0.237 \\
\hline Female & 9 & & & 23 & & & \\
\hline Male & 4 & & & 4 & & & \\
\hline Serum 4-HNE (pg/mL) & & $1.2 \pm 0.2$ & & & $1.5 \pm 0.3$ & & 0.001 \\
\hline Morning stiffness (min.) & & $82.3 \pm 81.7$ & $10-240$ & & $76.5 \pm 58.5$ & $10-240$ & 0.673 \\
\hline Pain (0-100 mm VAS) & & $45.1 \pm 28.2$ & $12-92$ & & $53.2 \pm 22.9$ & $12-94$ & 0.259 \\
\hline Patients global (0-100 mm VAS) & & $45.1 \pm 27.4$ & $8-90$ & & $53.9 \pm 23.2$ & $13-100$ & 0.272 \\
\hline Physicians global (0-100 mm VAS) & & $40.6 \pm 35.1$ & $5-96$ & & $49.6 \pm 28.4$ & $10-92$ & 0.319 \\
\hline Erythrocyte sedimentation rate $(\mathrm{mm} / \mathrm{h})$ & & $34.2 \pm 19.6$ & $6-68$ & & $29.1 \pm 12.8$ & $11-61$ & 0.506 \\
\hline C-reactive protein $(\mathrm{g} / \mathrm{dL})$ & & $24.4 \pm 31.5$ & 3-109 & & $23.0 \pm 19.2$ & $3-69$ & 0.427 \\
\hline Disease Activity Score 28 & & $3.8 \pm 1.7$ & $1.96-6.66$ & & $4.2 \pm 1.4$ & $2.07-7.03$ & 0.319 \\
\hline Health Assessment Questionnaire $20(0-3)$ & & $1.1 \pm 0.8$ & $0.00-2.12$ & & $1.4 \pm 0.7$ & $0.25-3$ & 0.332 \\
\hline Modified Larsen Score (0-120) & & $19.8 \pm 6.6$ & $8-30$ & & $35.3 \pm 27.1$ & $8-114$ & 0.112 \\
\hline
\end{tabular}


Table 4. Comparison of patients with rheumatoid arthritis using prednisolone alone or in combination with methotrexate

\begin{tabular}{|c|c|c|c|c|c|c|c|}
\hline & \multicolumn{3}{|c|}{ Prednisolone $(\mathrm{n}=11)$} & \multicolumn{3}{|c|}{ Methotrexate + Prednisolone $(n=16)$} & \multirow[b]{2}{*}{$p$} \\
\hline & $\mathrm{n}$ & Mean \pm SD & Min-Max & $\mathrm{n}$ & Mean \pm SD & Min-Max & \\
\hline Age (years) & & $54.3 \pm 12.4$ & $25-70$ & & $51.7 \pm 10.0$ & $37-72$ & 0.797 \\
\hline Sex & & & & & & & 0.296 \\
\hline Female & 10 & & & 12 & & & \\
\hline Male & 1 & & & 4 & & & \\
\hline Duration of the disease (years) & & $5.2 \pm 3.8$ & $1-10$ & & $5.5 \pm 4.9$ & $1-16$ & 0.980 \\
\hline Prednisolone (mg/day) & & $8.4 \pm 4.4$ & $5-20$ & & $6.3 \pm 2.4$ & $2.5-10$ & \\
\hline Methotrexate (mg/week) & & $11.1 \pm 2.0$ & $7.5-15$ & & & & \\
\hline Erythrocyte sedimentation rate $(\mathrm{mm} / \mathrm{h})$ & & $45.8 \pm 16.8$ & $22-68$ & & $22.0 \pm 9.7$ & $6-40$ & 0.001 \\
\hline C-reactive protein $(\mathrm{g} / \mathrm{dL})$ & & $42.7 \pm 31.6$ & $6-109$ & & $11.8 \pm 12.8$ & $3-52$ & 0.003 \\
\hline Serum 4-HNE (pg/mL) & & $1.4 \pm 0.3$ & $1.02-2.01$ & & $1.4 \pm 0.3$ & $0.99-1.81$ & 0.928 \\
\hline
\end{tabular}

to lipid peroxidation have been documented in patients with RA than healthy control populations in previous studies. ${ }^{5,22-24}$ However, contrary results have also been reported. ${ }^{25}$

In our literature survey, we did not encounter any study which assessed the association between 4-HNE levels and disease activity in patients with RA. Available data only suggested a possible relationship between lipid peroxidation products, such as malondialdehyde, and disease activity in patients with RA. ${ }^{2,26-28}$ Based on our findings, we may assume that serum 4-HNE levels in RA patients are not directly correlated with inflammatory activation in patients with RA. Controversial results in the literature may stem from complex mechanism of action of lipid peroxidation involving more than one step in the pathogenetic process of inflammation.

In our study, a significant correlation was found between serum 4-HNE levels and modified Larsen scores which demonstrates possible association with joint damage. To the best of our knowledge, this association has not been assessed previously. A previous study by Bohanec Grabar et al. ${ }^{29}$ showed a correlation between oxidative stress and joint erosions. However, the authors did not use an objective or validated scoring system like modified Larsen method to assess erosions. Our results may shed light on our current understanding of the interaction between ROS and inflammatory processes. . $^{4,5,7,8}$

Our results also documented similar levels of 4-HNE in patients taking prednisolone alone or in combination with MTX as well as MTX vs. other DMARDs. The data are highly limited regarding the potential interaction between lipid preoxidation end-products and anti-rheumatic drugs, requiring further researches.

The main limitation of our study is its crosssectional design and relatively small sample size. On the other hand, the wide range of our exclusion criteria prevented inclusion of more patients into the study.

In conclusion, our study demonstrated increased serum levels of 4-HNE in patients with RA compared to healthy controls. We did not demonstrate an association between disease activity and 4-HNE; however, we showed a relationship between disease activity and joint damage. Our findings indicate the possible role of 4-HNE levels in RA disease process and possibly joint damage.

\section{Declaration of conflicting interests}

The authors declared no conflicts of interest with respect to the authorship and/or publication of this article.

\section{Funding}

The authors received no financial support for the research and/or authorship of this article.

\section{REFERENCES}

1. van Boekel MA, Vossenaar ER, van den Hoogen FH, van Venrooij WJ. Autoantibody systems in rheumatoid arthritis: specificity, sensitivity and diagnostic value. Arthritis Res 2002;4:87-93.

2. Kamanli A, Naziroğlu M, Aydilek N, Hacievliyagil C. Plasma lipid peroxidation and antioxidant levels in patients with rheumatoid arthritis. Cell Biochem Funct 2004;22:53-7. 
3. Desai PB, Manjunath S, Kadi S, Chetana K, Vanishree J. Oxidative stress and enzymatic antioxidant status in rheumatoid arthritis: a case control study. Eur Rev Med Pharmacol Sci 2010;14:959-67.

4. Biemond P, Swaak AJ, Koster JF. Protective factors against oxygen free radicals and hydrogen peroxide in rheumatoid arthritis synovial fluid. Arthritis Rheum 1984;27:760-5.

5. Ozgüneş H, Gürer H, Tuncer S. Correlation between plasma malondialdehyde and ceruloplasmin activity values in rheumatoid arthritis. Clin Biochem 1995;28:193-4.

6. Halliwell B. Reactive species and antioxidants. Redox biology is a fundamental theme of aerobic life. Plant Physiol 2006;141:312-22.

7. Uchida K. A lipid-derived endogenous inducer of COX-2: a bridge between inflammation and oxidative stress. Mol Cells 2008;25:347-51.

8. Selley ML, Bourne DJ, Bartlett MR, Tymms KE, Brook AS, Duffield AM, et al. Occurrence of (E)-4hydroxy-2-nonenal in plasma and synovial fluid of patients with rheumatoid arthritis and osteoarthritis. Ann Rheum Dis 1992;51:481-4.

9. Uchida K. 4-Hydroxy-2-nonenal: a product and mediator of oxidative stress. Prog Lipid Res 2003;42:318-43.

10. Esterbauer H, Schaur RJ, Zollner H. Chemistry and biochemistry of 4-hydroxynonenal, malonaldehyde and related aldehydes. Free Radic Biol Med 1991;11:81-128.

11. Kurien BT, Scofield RH. Autoimmunity and oxidatively modified autoantigens. Autoimmun Rev 2008;7:567-73

12. Naziroğlu M, Kökçam I, Yilmaz S. Beneficial effects of intraperitoneally administered alpha-tocopheryl acetate on the levels of lipid peroxide and activity of glutathione peroxidase and superoxide dismutase in skin, blood and liver of thermally injured guinea pigs. Skin Pharmacol Appl Skin Physio 2003;16:36-45.

13. Kökçam I, Naziroglu M. Effects of vitamin E supplementation on blood antioxidants levels in patients with Behçet's disease. Clin Biochem 2002;35:633-9.

14. Arnett FC, Edworthy SM, Bloch DA, McShane DJ, Fries JF, Cooper NS, et al. The American Rheumatism Association 1987 revised criteria for the classification of rheumatoid arthritis. Arthritis Rheum 1988;31:315-24.

15. Prevoo ML, van 't Hof MA, Kuper $\mathrm{HH}$, van Leeuwen MA, van de Putte LB, van Riel PL. Modified disease activity scores that include twenty-eight-joint counts. Development and validation in a prospective longitudinal study of patients with rheumatoid arthritis. Arthritis Rheum 1995;38:44-8.

16. Fransen J, Stucki G, van Riel PL. Rheumatoid arthritis measures: Disease Activity Score (DAS), Disease Activity Score-28 (DAS28), Rapid Assessment of Disease Activity in Rheumatology (RADAR), and Rheumatoid Arthritis Disease Activity Index (RADAI). Arthritis Rheum 2003;49:214-24.

17. Küçükdeveci AA, Sahin H, Ataman S, Griffiths B, Tennant A. Issues in cross-cultural validity: example from the adaptation, reliability, and validity testing of a Turkish version of the Stanford Health Assessment Questionnaire. Arthritis Rheum 2004;51:14-9.

18. Larsen A. How to apply Larsen score in evaluating radiographs of rheumatoid arthritis in long-term studies. J Rheumatol 1995;22:1974-5.

19. Frei B, Stocker R, Ames BN. Antioxidant defenses and lipid peroxidation in human blood plasma. Proc Natl Acad Sci U S A 1988;85:9748-52.

20. Uhlig S, Wendel A. The physiological consequences of glutathione variations. Life Sci 1992;51:1083-94.

21. Kumagai S, Jikimoto T, Saegusa J. Pathological roles of oxidative stress in autoimmune diseases. Rinsho Byori 2003;51:126-32. [Abstract]

22. Gambhir JK, Lali P, Jain AK. Correlation between blood antioxidant levels and lipid peroxidation in rheumatoid arthritis. Clin Biochem 1997;30:351-5.

23. Akyol O, Iscedilci N, Temel I, Ozgocmen S, Uz E, Murat $\mathrm{M}$, et al. The relationships between plasma and erythrocyte antioxidant enzymes and lipid peroxidation in patients with rheumatoid arthritis. Joint Bone Spine 2001;68:311-7.

24. Jaswal S, Mehta HC, Sood AK, Kaur J. Antioxidant status in rheumatoid arthritis and role of antioxidant therapy. Clin Chim Acta 2003;338:123-9.

25. Olivieri O, Girelli D, Trevisan MT, Bassi A, Zorzan P, Bambara LM, et al. Red blood cell susceptibility to lipid peroxidation, membrane lipid composition and antioxidant enzymes in patients with rheumatoid arthritis. J Rheumatol 1991;18:1263-4.

26. El-barbary MA, Abdel Khalek MA, Elsalawy AM, Hazaa SM. Assessment of lipid peroxidation and antioxidant status in rheumatoid arthritis and osteoarthritis patients. The Egyptian Rheumatologist 2011;33:179-85.

27. Baskol G, Demir H, Baskol M, Kilic E, Ates F, Kocer $\mathrm{D}$, et al. Assessment of paraoxonase 1 activity and malondialdehyde levels in patients with rheumatoid arthritis. Clin Biochem 2005;38:951-5.

28. Baskol G, Demir H, Baskol M, Kilic E, Ates F, Karakukcu C, et al. Investigation of protein oxidation and lipid peroxidation in patients with rheumatoid arthritis. Cell Biochem Funct 2006;24:307-11.

29. Bohanec Grabar P, Logar D, Tomsic M, Rozman B, Dolzan V. Genetic polymorphisms modifying oxidative stress are associated with disease activity in rheumatoid arthritis patients. Dis Markers 2009;26:41-8. 